Check for updates

Cite this: RSC Adv., 2017, 7, 53887

Received 13th October 2017

Accepted 13th November 2017

DOI: $10.1039 / \mathrm{c} 7 \mathrm{ra11296c}$

rsc.li/rsc-advances

\title{
Carbon nanospecies affecting amyloid formation $\dagger$
}

\author{
M. Holubova, ${ }^{\text {ab }}$ R. Konefat, ${ }^{a}$ Z. Moravkova, ${ }^{a}$ A. Zhigunov, ${ }^{a}$ J. Svoboda, ${ }^{a}$ O. Pop- \\ Georgievski, (DD a J. Hromadkova, ${ }^{a}$ O. Groborz, ${ }^{a}$ P. Stepanek ${ }^{a}$ and M. Hruby (DD *a
}

\begin{abstract}
Carbon nanospecies (CNPs) are of high interest in current research due to their many unique properties. They may be created by common processes, such as burning. Therefore, they can become potential contaminants and may have a negative impact on human health and the biosphere. Moreover, they may also catalyze protein misfolding and subsequent amyloid formation, which is extremely hard to treat. We investigated the influence of single-walled carbon nanotubes (SWNTs), fullerene $\left(\mathrm{C}_{60}\right)$, carbon quantum dots (CDs) and nanodiamonds (NDs) on amyloid formation. This research utilized the hen egg-white lysozyme (HEWL) as a model system. Fibrils were detected by fluorescence of thioflavin-T (ThT) or Nile red (NR) and the results were confirmed by transmission electron microscopy (TEM). We have found that NDs promoted amyloid fibril formation at all concentrations. The highest concentration of $\mathrm{C}_{60}$ (250 $\mu \mathrm{g} \mathrm{ml}^{-1}$ ) accelerated the process of fibrillation, while smaller concentrations (16 and $80 \mu \mathrm{g} \mathrm{ml}^{-1}$ ) prolonged the lag phase and were comparable to the control. SWNTs prolonged the lag phase of amyloid formation at all concentrations. CDs efficiently terminated the growth of amyloid fibrils. When we compared the amyloidogenicity of all four types of CNPs, the following trend was apparent: NDs > control $>\mathrm{C}_{60}>\mathrm{CDs}>$ SWNTs.
\end{abstract}

\section{Introduction}

Amyloidosis is a group of diseases associated with the deposition of normally soluble proteins in the form of insoluble amyloids. These amyloids deposit in various organs and tissues and cause their dysfunction and thus pose a major threat to human health..$^{1,2}$ However, not all amyloids are unhealthy and pathological. There are functional amyloids of specific proteins, which, for example, are used by mammals for the production of melanin $^{3}$ and in bacteria such as Escherichia coli to form scaffolding for biofilms. ${ }^{4}$ The high stability, organized character and nanometric dimensions of amyloids make them excellent candidates for the production of nanomaterials (e.g., wires, gels, scaffolds, liquid crystals, etc.) using a "bottom-up" approach. ${ }^{5}$

All amyloids share several physicochemical features such as a fibrillar morphology, secondary structure of the $\beta$-sheet, insolubility in common solvents and detergents, birefringence after staining with Congo red and resistance to proteases. The amino acid sequences and proteins structures associated with amyloidosis vary greatly ${ }^{6}$ even though they share some structural similarities especially in the phenylalanine-rich sequences responsible for self-assembly. ${ }^{7}$

${ }^{a}$ Institute of Macromolecular Chemistry, Academy of Sciences of the Czech Republic, Heyrovský Sq. 2, 16206 Prague 6, Czech Republic. E-mail: mhruby@centrum.cz ${ }^{b}$ Charles University in Prague, Faculty of Science, Albertov 6, 12843 Prague 2, Czech Republic

$\dagger$ Electronic supplementary information (ESI) available. See DOI: $10.1039 / \mathrm{c} 7 \mathrm{ra} 11296 \mathrm{c}$
The formation of amyloid fibrils is a very complex process and short peptides are used for closer study of these processes. Peptides that are certain fragments of the precursor protein also have the ability to generate typical amyloid fibrils. A common feature of short peptides generating amyloid fibrils is the high occurrence of aromatic residues, ${ }^{8}$ showing that $\pi-\pi$ interactions play an important role in the formation of amyloid fibrils. Hydrophobic interactions are among the significant interactions in the aggregation and stabilization of amyloid fibrils., ${ }^{9,10}$ Furthermore, electrostatic interactions have other effects on fibrillation and stabilization., ${ }^{9,11}$

Carbon nanospecies (CNPs), such as fullerenes $\left(\mathrm{C}_{60}\right)$, carbon quantum dots (CDs), single- (SWNTs) and multiwalled carbon nanotubes (MWNTs), or nanodiamonds (NDs), are of high interest in current research due to their many unique properties. These nanomaterials are produced by high-tech methods; meanwhile they may also be created by common processes (Fig. 1), such as the burning and pyrolysis of organic materials, arc discharge welding and explosions. Therefore, CNPs can occur in nature and become potential contaminants, ${ }^{12}$ but their amyloidogenicity is still not sufficiently clear.

$\mathrm{C}_{60}$ is a stable compound consisting of 60 carbon atoms (molecular weight $720.66 \mathrm{~g} \mathrm{~mol}^{-1}$ ) with a diameter of approximately $0.7 \mathrm{~nm}$, which is roughly the size of many active pharmaceutical ingredients. Thirty carbon-carbon double bonds are present in the structure, to which free radicals can easily be added. $^{13}$

SWNTs have a typical diameter of between $1 \mathrm{~nm}$ (approximately 10 atoms around the cylinder) to $5 \mathrm{~nm}$, with a tube 


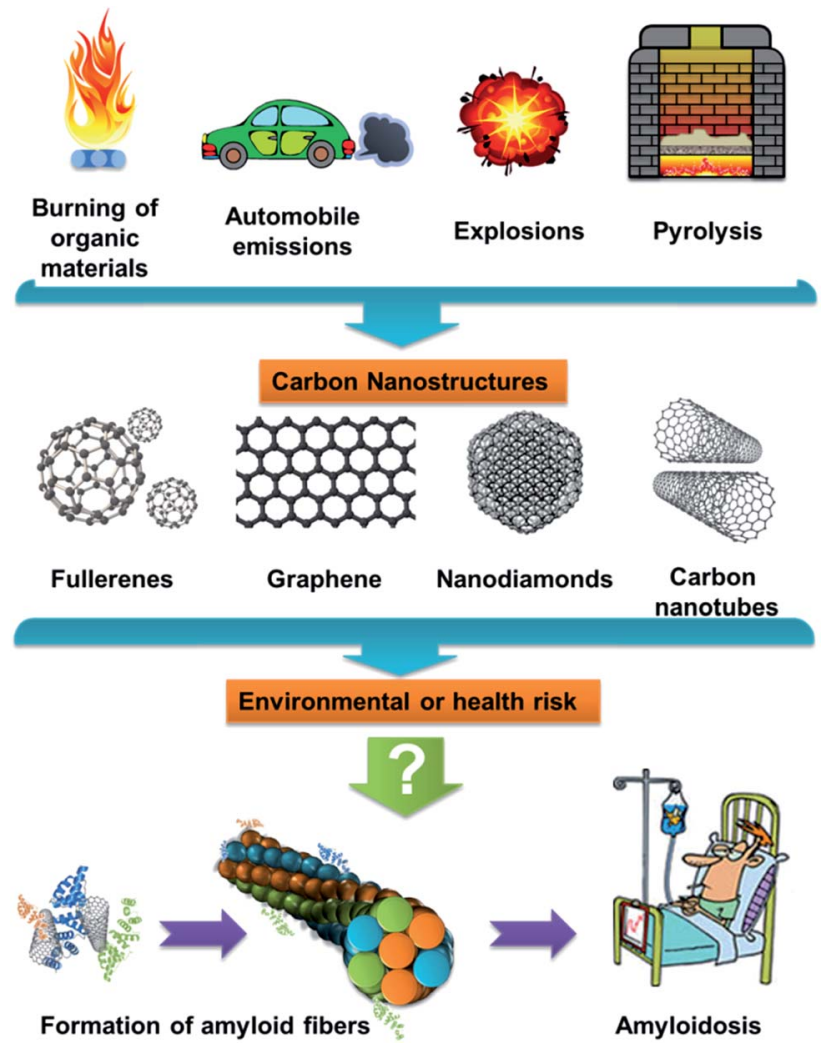

Fig. 1 Scheme of potential paths of CNPs.

length that can range from $1 \mathrm{~nm}$ to $1 \mathrm{~mm}$. During their synthesis, $\mathrm{Co}, \mathrm{Fe}, \mathrm{Ni}$, and Mo are used as catalyzers, which may appear in the final product as residual metal contaminants. ${ }^{14}$ $\mathrm{C}_{60}$ (ref. 13) and SWNTs ${ }^{15}$ contain $\mathrm{sp}^{2}$-hybridized carbon and therefore may be amyloidogenic, as the aromatic interactions play a key role in amyloid fibrils formation, they may also inhibit amyloid fibrils formation.

NDs consist of $\mathrm{sp}^{3}$-hybridized carbon and surface groups. They can occur in different size ranges with positive or negative charges depending on their production method. ${ }^{16}$ NDs have been synthesized most commonly using a detonation technique, ${ }^{17,18}$ but they can also be formed with chemical vapor deposition ${ }^{18,19}$ or laser ablation. ${ }^{19}$ NDs have interesting properties such as superior hardness and Young's modulus, and optical properties. ${ }^{19}$ NDs additives have been used for electrolytic metal plating for many years. More recently, they have been used in other applications such as in magnetic resonance imaging, chromatography, tribology; nanocomposites; drug delivery and other applications..$^{19,20}$

CDs are a type of carbon-based fluorescent nanomaterials with sizes under $10 \mathrm{~nm}$. When comparing CDs with traditional semiconductor quantum dots and organic dyes, CDs are superior in terms of their high solubility in water, facile modification and high resistance to photobleaching. They have excellent biological properties such as low toxicity and good biocompatibility facilitating their application in bioimaging and biomolecule/drug delivery systems. There is a wide range of applications for CDs. Because they have excellent electrical properties as electron donors and acceptors, causing chemiluminescence and electrochemical luminescence, they could be used in optoelectronics or sensors. ${ }^{21,22}$ CDs can be prepared by "top-down" or "bottom-up" methods. The "top-down" methods are based on carving bulk carbon materials into nanoparticles using physical or chemical approaches, such as acid oxidation, electrochemical and hydrothermal methods. ${ }^{23-27}$ Compared with "top-down" methods, the "bottom-up" methods have obvious advantages in adjusting the composition and physical properties of CDs through the careful selection of different organic precursors and carbonization conditions. "Bottom-up" methods include microwave irradiation, hydrothermal/solvothermal treatment or pyrolysis. ${ }^{23,28,29}$ The microwave irradiation of proper carbon sources has many advantages e.g., low cost, speed, efficiency and ease of production. ${ }^{30,31}$ Very often, natural sources (glucose, ${ }^{24,32,33}$ fructose, ${ }^{32}$ citric acid, ${ }^{24,34,35}$ urea $^{24,36}$ and amino acids ${ }^{37,38}$ ) are used for the preparation of CDs. Thanks to these known facts, CDs are likely to appear even in common processes that occur during cooking.

The hen egg-white lysozyme (HEWL) is a small protein with four disulfide bonds. ${ }^{39}$ This protein has been studied as a model of the human lysozyme, ${ }^{40}$ whose mutation (sharing $60 \%$ of its sequence identity with HEWL) is associated with hereditary systemic amyloidosis. ${ }^{41}$ The release of CNPs into the environment may occur as a results of common processes, such as CNPs production, CNP-containing product manufacturing, and the use and reuse of CNPs products. ${ }^{42}$ Therefore, they may have a negative impact on humans and the biosphere. Moreover, they may also catalyze protein misfolding and subsequent amyloid formation, which are extremely hard to treat. Testing for amyloidogenicity has already been carried out with some CNPs, ${ }^{43}$ but comparisons of CNPs have never been carried out on one type of protein model system. Based on all the previous information, we decided to study and compare the effects of several selected CNPs (SWNT, $\mathrm{C}_{60}$, NDs and CDs) on HEWL to determine their risks and study their amyloidogenicity. The obtained results may be useful for the production of CNPs and their subsequent use.

\section{Results and discussion}

First, we made a detailed characterization of prepared CDs. For other types of particles (NDs, SWNTs, $\mathrm{C}_{60}$ ), we performed a brief characterization before testing them on HEWL.

\section{Carbon quantum dots}

The CDs were obtained a black-brown solution, which was diluted to a light-yellow solution $(0.0005 \mathrm{wt} \%)$ with blue emission under a UV lamp with a wavelength of $366 \mathrm{~nm}$. The measured $\zeta$-potential of the CDs was $-31.2 \mathrm{mV}$. Elemental analysis (EA) revealed the composition of the CDs to be C $41.94 \mathrm{wt} \%, \mathrm{H} 4.33 \mathrm{wt} \%, \mathrm{~N} 19.36 \mathrm{wt} \%$ and $\mathrm{O}$ (calculated) $34.38 \mathrm{wt} \%$.

For measuring the spectra, we used an aqueous solution with a concentration $0.005 \mathrm{wt} \%$ CDs. It has a broad absorption spectrum with maxima at $273 \mathrm{~nm}, 344 \mathrm{~nm}$ and $404.5 \mathrm{~nm}$ (Fig. 2A). 

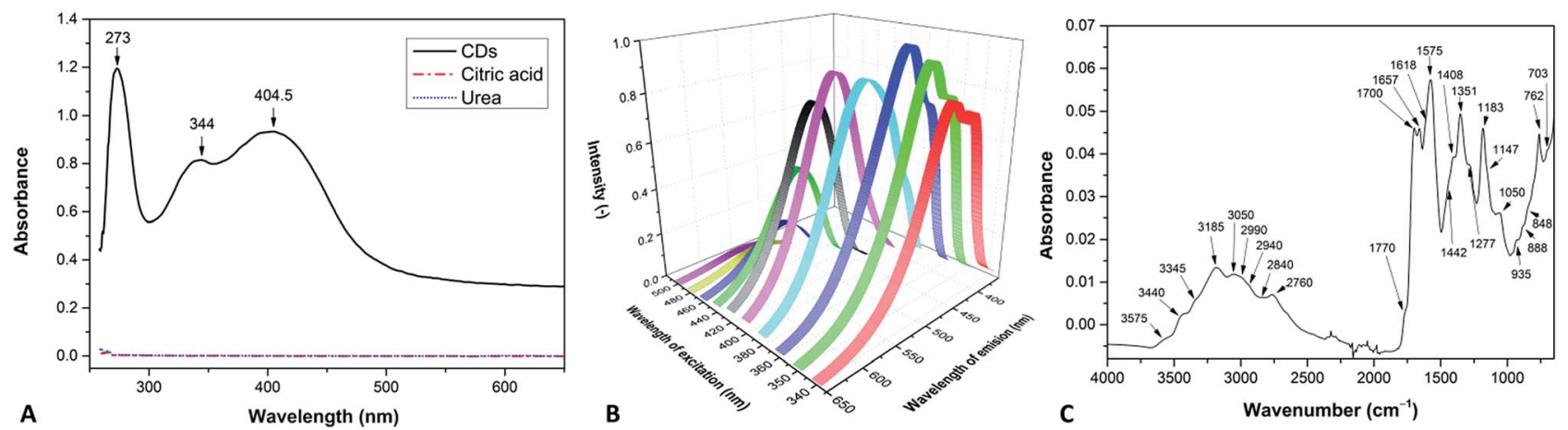

Fig. 2 (A) UV-Vis absorption spectrum, (B) PL spectra at various excitation wavelengths and (C) FTIR spectrum of the CDs.

It exhibits excitation-wavelength-dependent photoluminescence (PL) properties ranging from $455 \mathrm{~nm}$ (blue) to $549 \mathrm{~nm}$ (green) at excitations from $340 \mathrm{~nm}$ to $500 \mathrm{~nm}$. The strongest fluorescence emission band located at $460 \mathrm{~nm}$ is observed for $360 \mathrm{~nm}$ excitation (Fig. 2B).

The functional groups were detected by Fourier transform infrared (FTIR) spectroscopy (Fig. 2C). The spectra were determined using tables in the literature. ${ }^{44}$ The structural band spreading from 3500 to $2600 \mathrm{~cm}^{-1}$ belongs to the $\mathrm{O}-\mathrm{H}$ and $\mathrm{N}-\mathrm{H}$ stretching vibrations, with a contribution of the $\mathrm{C}-\mathrm{H}$ stretching vibrations at approximately $2760 \mathrm{~cm}^{-1}$. The bands at 1770 and $1700 \mathrm{~cm}^{-1}$ are attributed to $\mathrm{C}=\mathrm{O}$ stretching vibrations (in oxoand carboxylic groups, respectively), $\mathrm{C}=\mathrm{N}$ stretching vibration appears as a band at $1657 \mathrm{~cm}^{-1}$. The N-H deformation vibration absorbs approximately $1575 \mathrm{~cm}^{-1}$. The group of bands approximately $1351 \mathrm{~cm}^{-1}$ is due to $\mathrm{C}-\mathrm{H}$ and $\mathrm{O}-\mathrm{H}$ deformation vibrations, and contributions from the aromatic $\mathrm{C}=\mathrm{N}$ stretching are also possible. The band at $1183 \mathrm{~cm}^{-1}$ is assigned to the $\mathrm{C}-\mathrm{N}$ stretching vibration and the band at $1050 \mathrm{~cm}^{-1}$ corresponds to the $\mathrm{C}-\mathrm{O}$ stretching vibration. Absorption in the region below $1000 \mathrm{~cm}^{-1}$ is caused by out-of-plane $\mathrm{O}-\mathrm{H}$ and $\mathrm{N}-\mathrm{H}$ deformation vibrations and skeletal vibrations of the $\mathrm{O}-$ and $\mathrm{N}$ rich carbon materials.

The composition of the CDs was examined by X-ray photoelectron spectroscopy (XPS) and EA (Table 1). The well-

Table 1 Composition of the CDs determined by XPS and elemental analysis. For the sake of comparison with XPS, the oxygen content in the CDs from the EA was obtained by subtracting $\mathrm{C}, \mathrm{H}$ and $\mathrm{N}$ from $100 \mathrm{wt} \%$

\begin{tabular}{|c|c|c|c|c|}
\hline & Functionality & $\begin{array}{l}\text { XPS individual } \\
\text { contributions [wt } \%]\end{array}$ & $\begin{array}{l}\text { XPS total } \\
{[\mathrm{wt} \%]}\end{array}$ & $\begin{array}{l}\text { EA } \\
{[\mathrm{wt} \%]}\end{array}$ \\
\hline \multirow[t]{5}{*}{$\mathrm{C}$} & $\underline{\mathrm{C}}=\mathrm{C}$ & $10.1 \pm 1.3$ & $50.1 \pm 0.8$ & $43.9 \pm 0.1$ \\
\hline & $\underline{\mathrm{C}}-\mathrm{C}$ & $14.4 \pm 1.2$ & & \\
\hline & $\underline{\overline{\mathrm{C}}}-\mathrm{N}, \underline{\mathrm{C}}-\mathrm{O}$ & $6.2 \pm 0.1$ & & \\
\hline & $\underline{\overline{\mathrm{C}}}=\mathrm{O}$ & $18.5 \pm 0.4$ & & \\
\hline & $\overline{\mathrm{C}}(=\mathrm{O})-\mathrm{O}$ & $0.9 \pm 0.2$ & & \\
\hline \multirow[t]{2}{*}{$\mathrm{N}$} & C- $\underline{N}$ & $17.7 \pm 0.5$ & $19.9 \pm 0.6$ & $20.2 \pm 0.1$ \\
\hline & $\mathrm{C}-\overline{-} \underline{\mathrm{N}}{ }_{3}{ }^{+}$ & $2.2 \pm 0.3$ & & \\
\hline \multirow[t]{2}{*}{$\mathrm{O}$} & $\underline{\mathrm{O}}=\mathrm{C}$ & $27.1 \pm 0.5$ & $30.0 \pm 0.3$ & $35.9 \pm 0.1$ \\
\hline & $\underline{\overline{\mathrm{O}}}-\mathrm{C}$ & $2.9 \pm 0.4$ & & \\
\hline
\end{tabular}

corroborated data were further supplemented by determining the covalent structure of the individual functionalities giving rise to characteristic features in the high resolution $\mathrm{C} 1 \mathrm{~s}, \mathrm{~N} 1 \mathrm{~s}$ and $\mathrm{O}$ 1s XPS spectra of the CDs (Fig. 3). The C 1s envelope could be resolved with contributions arising from $\mathrm{sp}^{2}, \mathrm{sp}^{3}, \mathrm{C}-\mathrm{N}$ and $\mathrm{C}-\mathrm{O}, \mathrm{C}=\mathrm{O}$ and $\mathrm{C}(=\mathrm{O})-\mathrm{O}$ moieties centered at 284.3, 285.0, 286.7, 288.1 and $289.9 \mathrm{eV}$, respectively. ${ }^{45}$ The $\mathrm{N}$ 1s envelope was characterized by a dominant $\mathrm{C}-\underline{\mathrm{N}}$ contribution at $399.7 \mathrm{eV}$ and charged $\mathrm{C}-\mathrm{NH}_{3}{ }^{+}$moieties at $401.3 \mathrm{eV}$, thus verifying the nitrogen doping of the performed CDs arising from urea. Concomitantly, the $\mathrm{O} 1 \mathrm{~s}$ spectrum showed the presence of carbonyl $\underline{\mathrm{O}}=\mathrm{C}$ moieties at $531.4 \mathrm{eV}$ and $\underline{\mathrm{O}}-\mathrm{C}$ moieties of the hydroxyl and ether groups at $533.3 \mathrm{eV}$. The XPS results indicate that the surface structure of the CDs is heterocyclic with aliphatic defects mainly reflected in $\mathrm{sp}^{3}$ carbon species.

Small-angle X-ray scattering (SAXS) was used to characterized the CDs in water. Form Fig. 4, one can see the scattering curves, corresponding to the samples with $3 \mathrm{wt} \%, 5 \mathrm{wt} \%, 7.5 \mathrm{wt} \%$ and $10 \mathrm{wt} \% \mathrm{CD}$ contents. The intensity was normalized by the concentration. The curves coincide at larger $q$-values. The intensity slope in this region is approximately 2.5 , which indicates rough interface. The influence of the concentration is clearly visible at the lower $q$-region, where we note difference in the intensity upturn. Such behavior means that the CDs were partially aggregated, and if we assume the same shape, the 


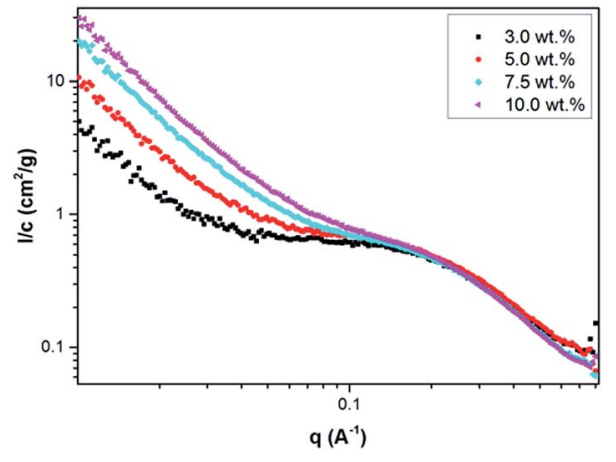

Fig. 4 SAXS curves, normalized by concentration, corresponding to $3.0 \mathrm{wt} \%$ (black squares), $5.0 \mathrm{wt} \%$ (red rings), $7.5 \mathrm{wt} \%$ (light-blue rhombi) and $10 \mathrm{wt} \%$ (pink triangles) CDs in water.

aggregates size is smaller for the lower concentration sample. The radius of gyration for the separated particles, which are clearly observed as a shoulder in the middle $q$-range, is approximately $R_{\mathrm{g}}=6.8 \AA$ for all the concentrations. Assuming spherical objects the radius could be calculated as

$$
R=\sqrt{\frac{5 R_{\mathrm{g}}{ }^{2}}{3}}
$$

That will give us the volume, $V=2835 \AA^{3}$. As expected, the intensity, extrapolated to $q=0, I_{0}$, was roughly the same for all solutions. On the $I / c$ scale, we obtained $I_{0}=0.77 \mathrm{~cm}^{2} \mathrm{~g}^{-1}$. According to the equation for determining the molecular weight,

$$
M_{\mathrm{w}}=\frac{I_{0}}{c} \frac{N_{\mathrm{A}}}{\Delta b^{2}}
$$

where $c$ is concentration, $\Delta b^{2}$ is scattering contrast and $N_{\mathrm{A}}$ is Avogadro's number. One should know the density of the particles in order to calculate the scattering contrast, but we were not sure about this value. Also due to the presence of aggregates, it was impossible to estimate the scattering contrast of the particles from invariant, ${ }^{46}$ but we were observing the higher transmittance for the higher concentrations and that means that the linear absorption coefficient of the CDs is lower than for water. To fulfill this observation particle density should be lower than $1.5 \mathrm{~g} \mathrm{~cm}^{-3}$. The knowing transmission and the sample thickness (measured by optical microscope), we have estimated the density approximately $1.3 \mathrm{~g} \mathrm{~cm}^{-3}$. Now we could calculate the scattering contrast and the molecular weight of the particles, which was $1817 \mathrm{~g} \mathrm{~mol}^{-1}$.

The last characterization method was nuclear magnetic resonance (NMR) spectroscopy. Fig. 5 shows ${ }^{1} \mathrm{H}$ NMR and ${ }^{13} \mathrm{C}$ NMR high-resolution spectra of the $\mathrm{CDs}$ in a $\mathrm{D}_{2} \mathrm{O}$ solution measured at $295 \mathrm{~K}$. In the ${ }^{1} \mathrm{H}$ NMR spectrum (Fig. 5 up), a strong solvent signal at $\delta=4.8 \mathrm{ppm}$ and a group of signals between $\delta=2-4 \mathrm{ppm}$. These signals are related to proton groups with electronegative atoms in nearby, such as nitrogen and oxygen, as well as proton groups next to carbonyl groups $(\mathrm{C}=\mathrm{O})$. Additionally, the single peak detected at $\delta=6 \mathrm{ppm}$ can be related to the proton from $\mathrm{HC}=$ group. Signals related to the
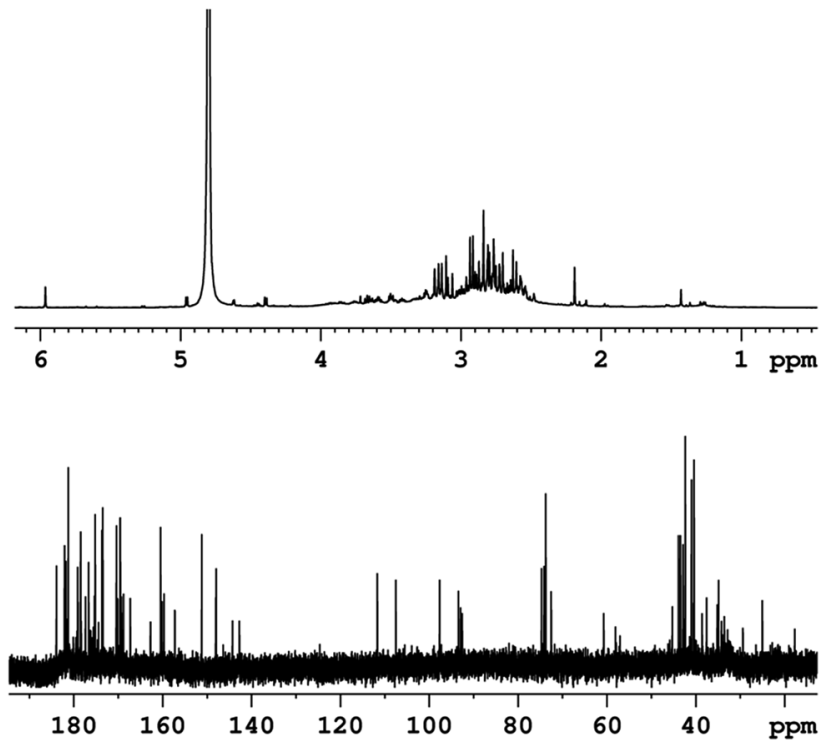

Fig. $5{ }^{1} \mathrm{H}$ NMR (up) and ${ }^{13} \mathrm{C}$ NMR spectra (down) of the CDs in a $\mathrm{D}_{2} \mathrm{O}$ solution.

$\mathrm{OH},(\mathrm{C}=\mathrm{O})-\mathrm{OH}, \mathrm{NH}$ and $\mathrm{NH}_{2}$ groups should not appear at the spectrum due to rapid chemical exchanges with the solvent. The ${ }^{13} \mathrm{C}$ NMR spectrum (Fig. 5 bottom) allows us to distinguish carbon atoms with different functionalities. Similar to the proton spectrum, carbons directly neighboring electronegative atoms $(\mathrm{N}, \mathrm{O})$, or $\mathrm{C}=\mathrm{O},(\mathrm{C}=\mathrm{O})-\mathrm{O}$, and $\mathrm{C}=\mathrm{N}$ groups are detected at $\delta=20-80 \mathrm{ppm}$. In the chemical shift range of $\delta=80-$ 120 ppm signals from $\mathrm{C}=\mathrm{C}$ carbons were observed. The existence of carboxylic acid $((\mathrm{C}=\mathrm{O})-\mathrm{OH})$, carboxylate ester $((\mathrm{C}=\mathrm{O})-$ $\mathrm{O})$, amide $((\mathrm{C}=\mathrm{O})-\mathrm{N})$ and imine $(\mathrm{C}=\mathrm{N})$ groups is suggested by the signals detected in the range $\delta=140-185 \mathrm{ppm}^{.{ }^{7}}$

\section{Morphology of carbon nanospecies}

Nanospecies suspensions with at concentrations of $1 \mathrm{mg} \mathrm{ml}^{-1}$ were measured with dynamic light scattering (DLS) showing nanospecies with some clusters, which were also observed by TEM. Nanospecies without surface stabilization tend to create larger clusters, resulting from the high hydrophobicity. In our case, we used SWNTs and $\mathrm{C}_{60}$ without surface stabilization to obtain data very close to data for environmental pollutants, as surface stabilization may significantly influence the amyloidogenic activity. The size of the SWNTs clusters was $120 \pm 16 \mathrm{~nm}$; however the aspect ratio of carbon nanotubes must be taken into account. Fig. 6A shows very long SWNTs. $\mathrm{C}_{60}$ fullerenes are spherical particles, but similar to SWNT, they formed clusters in the suspension. The size measured by DLS of these clusters was $373 \pm 86 \mathrm{~nm}$. Fig. $6 \mathrm{~B}$ shows only clusters of $\mathrm{C}_{60}$ that correspond to value measured with DLS. These clusters are similar to clusters shown in the literature. ${ }^{48,49}$

In case of NDs, surface groups stabilize them in solution. The surface groups of the NDs were determined with FTIR, and in addition, Raman spectroscopy measurements were performed. The FTIR spectrum of the NDs (Fig. 7B) displays O-H stretching vibrations in the region above $3000 \mathrm{~cm}^{-1}$, and a weak band of 


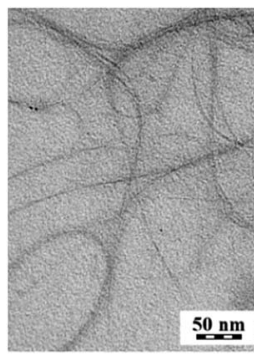

A

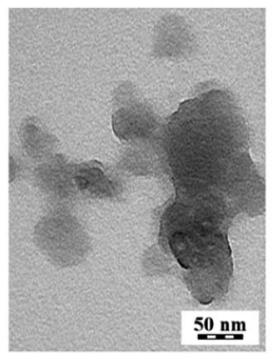

B

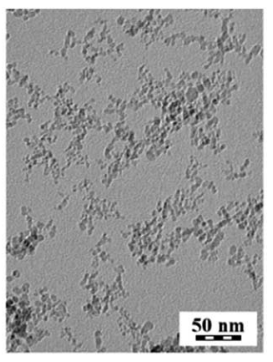

C
Fig. 6 TEM micrographs of (A) SWNTs, (B) $\mathrm{C}_{60}$ and (C) NDs.

A

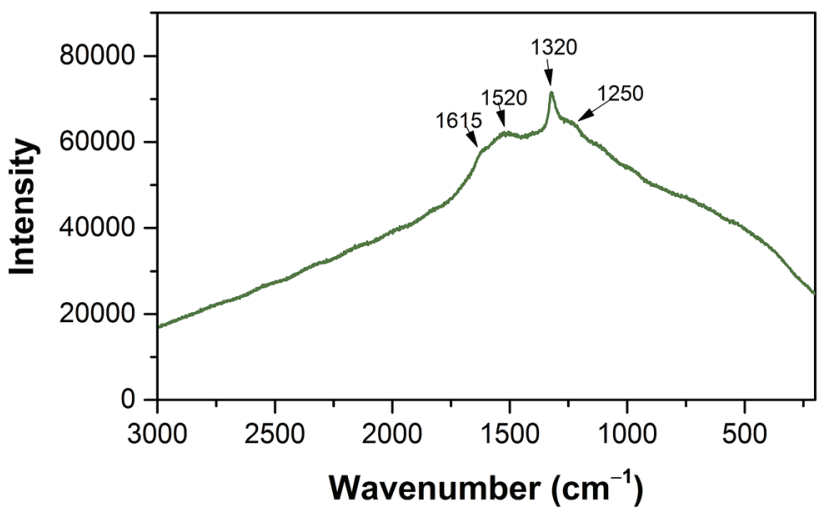

B

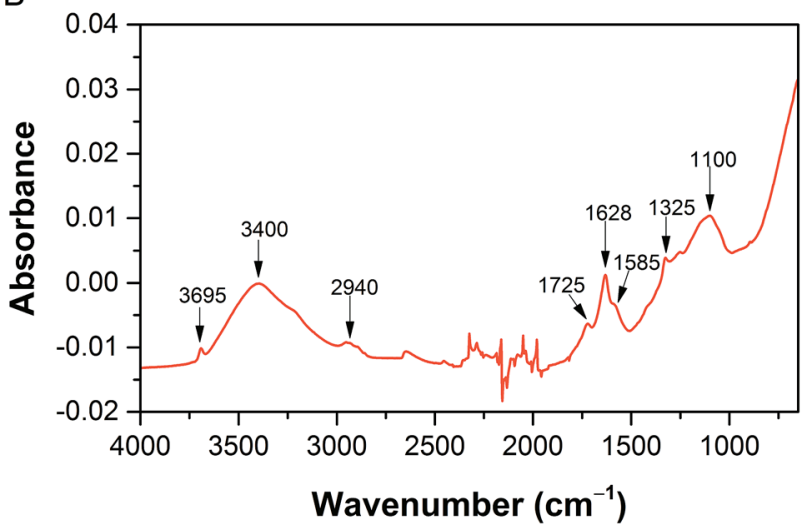

Fig. 7 (A) Raman and (B) FTIR spectra of the NDs.

$\mathrm{C}-\mathrm{H}$ stretching vibrations is also observed at $2940 \mathrm{~cm}^{-1} \cdot \mathrm{C}=\mathrm{O}$ stretching of the oxo- and carboxylic groups is observed at 1725 and $1628 \mathrm{~cm}^{-1}$ with a shoulder at $1585 \mathrm{~cm}^{-1}$. The band at $1325 \mathrm{~cm}^{-1}$ is due to $\mathrm{C}-\mathrm{H}$ and $\mathrm{O}-\mathrm{H}$ deformation vibrations and the band at $1050 \mathrm{~cm}^{-1}$ is a result of the $\mathrm{C}-\mathrm{O}$ stretching and $\mathrm{C}-\mathrm{H}$ bending vibrations. Oxygen-based side-groups such as carboxylic, oxo- or alcohol groups strongly dominate in the NDs.

In the Raman spectrum of the NDs (Fig. 7A), a peak of C-C stretching vibrations in $\mathrm{sp}^{3}$ carbon was detected at $1320 \mathrm{~cm}^{-1} .^{50}$ This proves the presence of the nanodiamond structure. In addition, broad bands at approximately 1250 (C-O stretching), 1520 (non-specific C-C stretching vibrations) and $1615 \mathrm{~cm}^{-1}$
( $\mathrm{C}=\mathrm{C}$ stretching of aliphatic structures) are visible. The bands typical of $\mathrm{sp}^{2}$ materials at 1330 and $1570 \mathrm{~cm}^{-1}$ are not resolved. Furthermore, the $\zeta$-potential, which is important for the interaction with proteins, was measured for an ND concentration of $1 \mathrm{mg} \mathrm{ml}^{-1}$ in water and was $+45 \pm 3 \mathrm{mV}$. Using DLS, the NDs were found to produce larger clusters $66 \pm 3 \mathrm{~nm}$ in size and a further peak for $13 \pm 5 \mathrm{~nm}$. The peak for smaller particles corresponds to individual nanodiamonds in Fig. 6C. The CDs are too small and have a low contrast in TEM and the grid, on which the sample is applied, is covered with carbon; therefore CDs could not be observed in TEM.

\section{Characterization and detection of amyloid fibrils}

The generation of amyloid fibrils is much faster in vitro than in vivo, ${ }^{51}$ but they share the some structure features. The surface of CNPs was not additionally modified to model environmentrelated situation as closely as possible.

The most common marker used for the rapid detection of amyloid fibrils is thioflavin $\mathrm{T}$ (ThT), which shows a huge fluorescence enhancement upon binding to amyloid aggregates, ${ }^{52-54}$ but it does not interact with amyloid oligomers and protofibrils. ${ }^{50}$ ThT is a charged molecule, therefore its binding property is different at acidic and neutral $\mathrm{pH}^{55} \mathrm{~A}$ very old method for detecting amyloid in tissues is Congo red staining. The Congo red staining procedure requires the use of polarized light microscopy. The diagnostic "apple green birefringence" may be difficult to visualize and therefore show low sensitivity. Unlike Congo red stain, the experiments with the ThT staining are very easy to perform and the results are much more straightforward to interpret. Another advantage of the ThT is that it detects even very small amounts of amyloid fibrils, where Congo red stain may be doubtful or false negative. ${ }^{56}$

Nile red (NR) can be used to detect amyloid in vitro. NR is an uncharged, heterocyclic fluorescence dye..$^{55} \mathrm{NR}$ does not change fluorescence in the presence of oligomeric states while targeting more mature fibrils. ${ }^{57}$ The results obtained from fluorescence must be confirmed by another method and the most appropriate method for a small amount of sample is TEM. TEM micrographs can be used for the qualitative comparison of features, such as the twists in ribbon-like fibrils, curvature fibril and surface smoothness. TEM micrographs can also be used for quantitative analysis, including the length of early aggregates and seeds, the width of fibrils, the number of protofilaments and the periodicity of fibril twists. ${ }^{58}$ We used negative staining for all our experiments. This negative staining yields samples with improved contrast and well-preserved morphologies, because the stain not only provides contrast but also protects the sample from radiation damage. ${ }^{58}$

For our experiments, we used the fluorescence of either ThT or NR for quantification. The measured values for the samples were related to the blank that did not contain any fibrils, only the dye. TEM quantification is very complex, so we used TEM micrographs only to determine the morphology of the sample whether it was amyloid fibrils or other formations.

We chose ThT for experiments with the SWNTs, $\mathrm{C}_{60}$ and NDs, because ThT is more sensitive at the beginning of the 
process of fibrillation. ThT cannot be used for experiments with the CDs because the spectra of ThT and CDs overlap. Based on this information we chose NR for experiments with the CDs. The CDs have a very low fluorescence even in the NR region, but NR by fluorescence exceeds CDs and therefore it can be used.

We decided to use dichloromethane (DCM) for the preparation of the dispersion, which was removed by evaporation to not influence the process of fibrillation. The dispersions were characterized with TEM and DLS (see previous sections). The stock suspensions of SWNTs and $\mathrm{C}_{60}$ were prepared at a concentration of $1 \mathrm{mg} \mathrm{ml}{ }^{-1}$. These suspensions were added to individual vials with the HEWL solution. In all samples and in the control, the amount of DCM was same value, so DCM for all the samples was bubbled with nitrogen for the same amount of time. The samples were incubated and characterized at certain times.

Fig. 8 shows a graph of the relative fluorescence of ThT for different concentrations of SWNTs and $\mathrm{C}_{60}$ at different times. The graph shows that the highest concentration of $\mathrm{C}_{60}$ $\left(250 \mu \mathrm{g} \mathrm{ml}^{-1}\right)$ accelerated the fibrillation process. On the other hand lower concentrations of $\mathrm{C}_{60}\left(16\right.$ and $\left.80 \mu \mathrm{g} \mathrm{ml}^{-1}\right)$ revealed a statistically significant deceleration of the onset of amyloid fibril formation (i.e., prolonging the lag phase of amyloid fibril formation, most plausibly by the depletion of the seeds via preferential adsorption on the carbon nanospecies). After a short time, the difference disappears and the samples are comparable to the control. The TEM micrographs of all samples of $\mathrm{C}_{60}$ (Fig. 9E-G) show the typically long fibers seen in the control (Fig. 9A). In these pictures there are also some spherical particles, but these are probably artifacts that occurred during the sample preparation. The results for SWNTs differ from $\mathrm{C}_{60}$. The graph (Fig. 8) shows a statistically stronger deceleration of the process of fibrillation for all samples by SWNTs compared to $\mathrm{C}_{60}$, significantly prolonging the lag phase of amyloid formation, most plausibly by depleting the seeds via preferential adsorption on the carbon nanospecies as mentioned above for

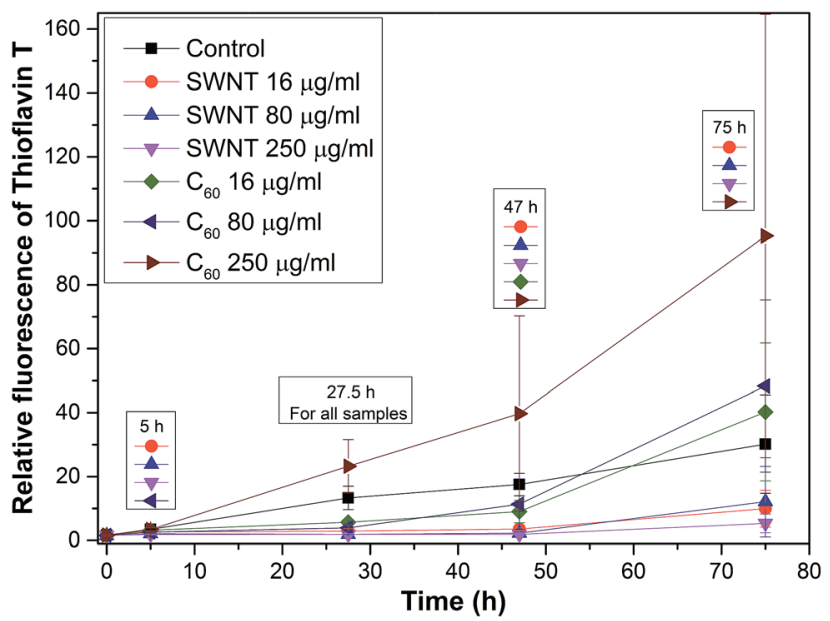

Fig. 8 A Graph of the relative fluorescence of thioflavin $T$ in experiments with SWNTs and $\mathrm{C}_{60}$, where the legend above the results from the same time represents a statistically significant difference $(\alpha<0.05)$ when compared to a control at this certain time.
$\mathrm{C}_{60}$. These results are supported by TEM micrographs of samples with SWNTs (Fig. 9B-D). The TEM micrograph for the $16 \mu \mathrm{g} \mathrm{ml}^{-1}$ concentration SWNTs (Fig. 9B) shows typically long fibers seen in the control (Fig. 9A), but a higher concentration (80 $\mu \mathrm{g} \mathrm{ml}^{-1}$ SWNTs) reveals shorter fibrils (Fig. 9C). The highest concentration $\left(250 \mu \mathrm{g} \mathrm{ml} \mathrm{m}^{-1}\right.$ SWNTs, Fig. 9D) had different morphology than of the control (Fig. 9A). This picture shows a fibrillary morphology, but the fibrils are thick. It seems that the growth of the fibrils is terminated on the surface of the SWNT.

NDs were used in a second experiment. The NDs suspension had $10 \mathrm{mg} \mathrm{ml}^{-1}$ concentration in water. This suspension was added to the individual vials with the HEWL solution. In all samples and the control, the amount of HEWL was same value. The samples were incubated and characterized at certain times.

Fig. 10 shows a graph of the relative fluorescence of ThT for different concentrations of NDs at different times. The graph show that all ND concentrations, except for the lowest concentration $\left(16 \mu \mathrm{g} \mathrm{ml} \mathrm{m}^{-1}\right)$, significantly accelerated the process of fibrillation by shortening the lag phase, i.e., by being efficient amyloid fibrillation initiators. This is interesting because the surface of the NDs is preferentially $\mathrm{sp}^{3}$-carbon based, thus not allowing the $\pi-\pi$ interactions that govern the amyloid formation. The TEM micrographs of all NDs samples (Fig. 11B-D) show long fibers as similar to in the control (Fig. 11A). In these pictures, some artifacts occurred during the preparation of the sample. Fig. 11E shows a thicker layer of fibrils, correlating to the results of the graph (Fig. 10). Based on these experiments, we can say that NDs initiate fibril growth but do not interfere in the elongation process. This finding is critical for the application of NDs in medicine.

Fig. 12 shows a graph which combines graphs from Fig. 8 and 10. Because the graph combines data from two experiments, the best combination method was the percent fibril formation. The method involves that a control at a certain time was taken as $100 \%$ and other data were calculated according to the control at this certain time. The obtained values were plotted. The graph shows a peak for all NDs samples. This peak may be due to the fact that the growth of fibrils in the presence of NDs is immediate while the control is in the lag phase (at the beginning of a fibril growth). After reaching a sufficient number of nuclei for the growth of fibrils in the control occurred the rapid growth of fibrils in the control, but the NDs samples already had a large amount of fibrils and the free protein gradually decreases in the samples to produce additional fibrils. A curve for the highest concentration of $\mathrm{C}_{60}\left(250 \mu \mathrm{g} \mathrm{ml}^{-1}\right)$ gradually rises accelerated the fibrillation process, which means the gradual growth of fibrils and this concentration accelerated the fibrillation process. On the other hand curves for lower concentrations of $\mathrm{C}_{60}$ (16 and $80 \mu \mathrm{g} \mathrm{ml}^{-1}$ ) show a decline from the beginning, and then begin to rise. This decrease can be explained by prolonging the lag phase of amyloid fibril formation due to protein adsorption on surface. The last three curves are for samples with SWNTs. The curves show a decline that means significantly prolonging the lag phase. The curves show the growth of the fibrils can be terminated on the surface of the SWNT. Based on this comparative graph (Fig. 12), the CNPs (SWNTs, $\mathrm{C}_{60}$, and NDs) and the control 


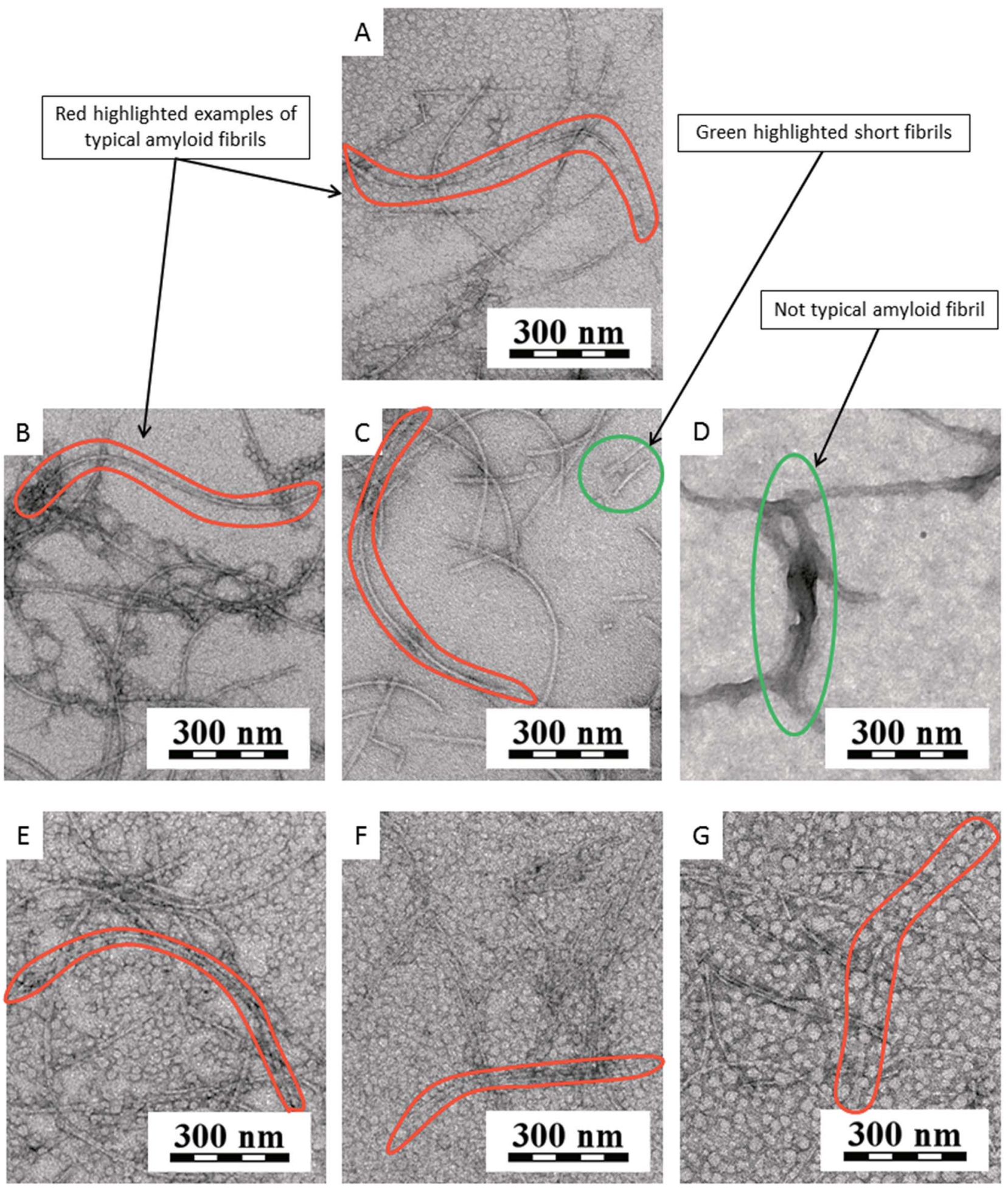

Fig. 9 TEM micrographs of experiments with SWNTs and $\mathrm{C}_{60}$ : (A) fibrils of HEWL (control) after $27.5 \mathrm{~h}$ of incubation without any nanospecies; (B) fibrils of HEWL after $27.5 \mathrm{~h}$ of incubation with $16 \mu \mathrm{g} \mathrm{ml}^{-1}$ SWNTs; (C) fibrils and shorter fibrils of HEWL after $27.5 \mathrm{~h}$ of incubation with $80 \mu \mathrm{g} \mathrm{ml} \mathrm{l}^{-1}$ SWNTs; (D) thick fibrils of HEWL after $27.5 \mathrm{~h}$ of incubation with $250 \mu \mathrm{g} \mathrm{ml}^{-1}$ SWNTs; (E) only long typically fibrils of HEWL after $27.5 \mathrm{~h}$ of incubation with $16 \mu \mathrm{g} \mathrm{ml}^{-1} \mathrm{C}_{60}$, (F) $80 \mu \mathrm{g} \mathrm{ml}^{-1} \mathrm{C}_{60}$ and (G) $250 \mu \mathrm{g} \mathrm{ml}^{-1} \mathrm{C}_{60}$.

can be ranked from the most amyloidogenic to least in the following order: NDs $>$ control $>\mathrm{C}_{60}>$ SWNTs.

CDs were used in the final experiment. The CDs were prepared as a lyophilized powder. From this powder, a suspension was prepared in water at a concentration $10 \mathrm{mg} \mathrm{ml}^{-1}$. This suspension was added to individual vials with the HEWL solution. In all samples and the control, the amount of HEWL was same value. The samples were incubated and characterized at certain times. 


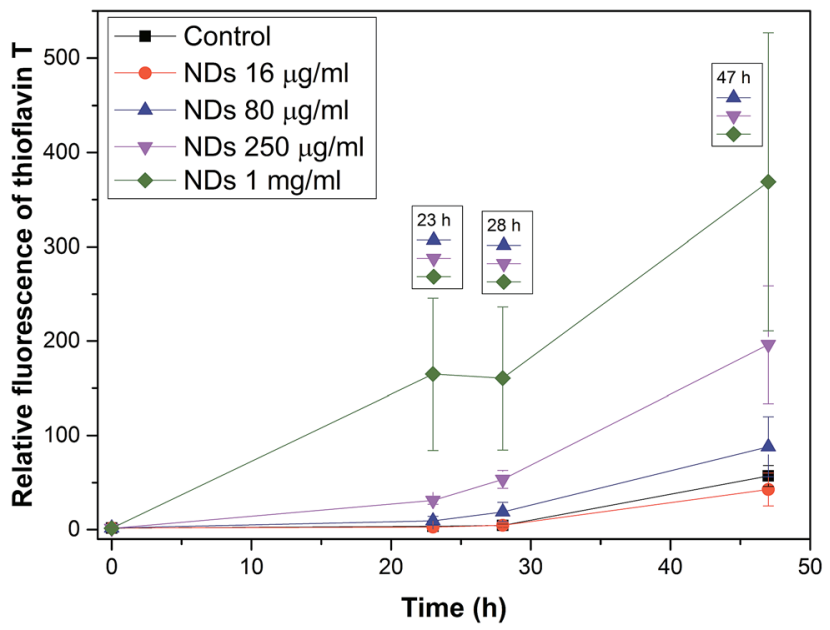

Fig. 10 A graph of the relative fluorescence of thioflavin $T$ in experiments with NDs, where the legend above the results from the same time represents a statistically significant difference $(\alpha<0.05)$ when compared to a control at this certain time.
Fig. 13 shows a graph of the relative fluorescence of NR for different concentrations of CDs at different times. We can see that the CDs significantly affect the process of fibrillation. There is a significant deceleration for almost all concentrations. The smallest concentration of CDs $\left(16 \mu \mathrm{g} \mathrm{ml}^{-1}\right)$ did not demonstrate any significant influence on the process. The difference from the control was only seen after a long time for the smallest concentration of the CDs. The other three concentrations of CDs $\left(80,250\right.$ and $\left.1000 \mu \mathrm{g} \mathrm{ml}^{-1}\right)$ significantly decelerated the process of fibrillation. After a long time, the concentration dependence of the process deceleration was demonstrated. These results support the TEM micrographs of the samples (Fig. 14B-E). Fig. 14A shows the TEM micrographs of the control. There are typically long fibrils. The next picture (Fig. 14B) shows typically long fibrils as seen in the control, however, for a higher concentration $\left(80 \mu \mathrm{g} \mathrm{m}{ }^{-1}\right.$, Fig. 14C), shorter fibrils occur. As the concentration increases, more short fibrils and clusters appear, as seen in Fig. 14D for a CDs concentration $250 \mu \mathrm{g} \mathrm{ml}^{-1}$. At the highest concentration $\left(1 \mathrm{mg} \mathrm{ml}{ }^{-1}\right)$, long fibril formation is completely suppressed. The TEM micrograph (Fig. 14E) of this sample shows a completely
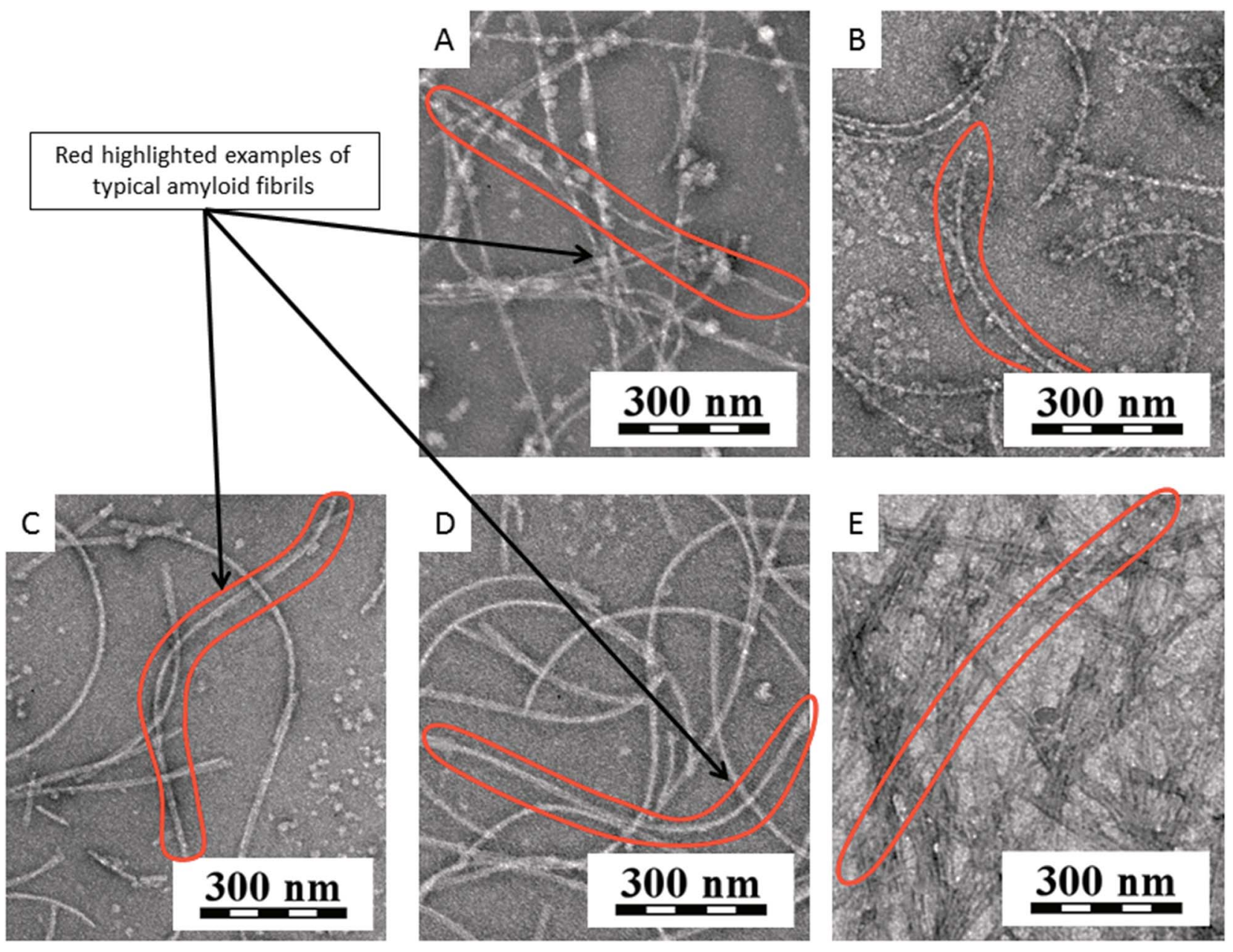

Fig. 11 TEM micrographs of experiments with NDs: (A) fibrils of HEWL (control) after $23 \mathrm{~h}$ of incubation without any nanospecies; (B) fibrils of HEWL after $23 \mathrm{~h}$ of incubation with $16 \mu \mathrm{g} \mathrm{ml}^{-1} \mathrm{NDs}$; (C) fibrils of HEWL after $23 \mathrm{~h}$ of incubation with $80 \mu \mathrm{g} \mathrm{ml} \mathrm{l}^{-1} \mathrm{NDs}$; (D) fibrils of HEWL after $23 \mathrm{~h}$ of incubation with $250 \mu \mathrm{g} \mathrm{ml}^{-1} \mathrm{NDs}$; (E) many fibrils of $\mathrm{HEWL}$ after $23 \mathrm{~h}$ of incubation with $1 \mathrm{mg} \mathrm{ml}^{-1} \mathrm{NDs}$. 


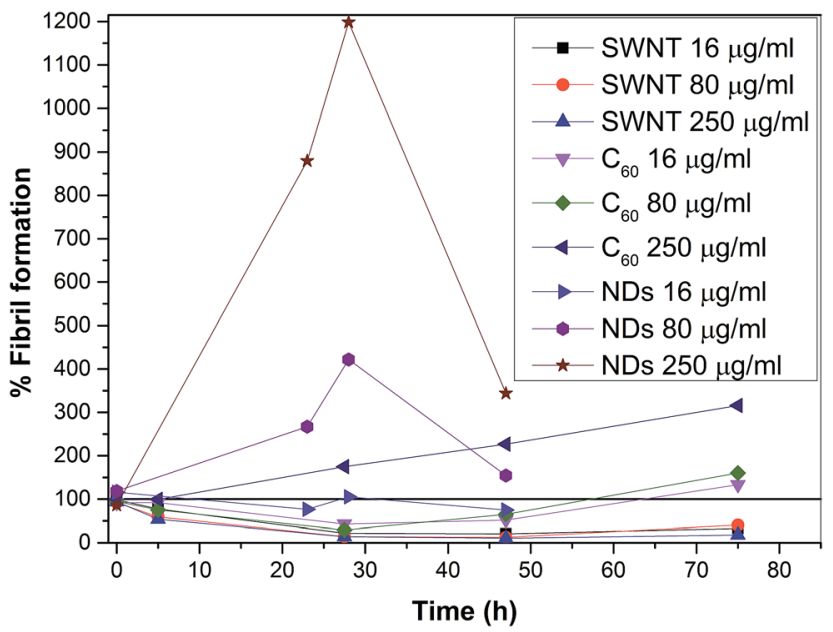

Fig. 12 The effect of different concentrations of CNPs on fibril formation. A graph combines the results from Fig. 8 and 10. The results were always related to a control at a certain time and this control was taken as $100 \%$. The results were displayed without NDs $1 \mathrm{mg} \mathrm{ml}^{-1}$ and error bars for a clearer view.

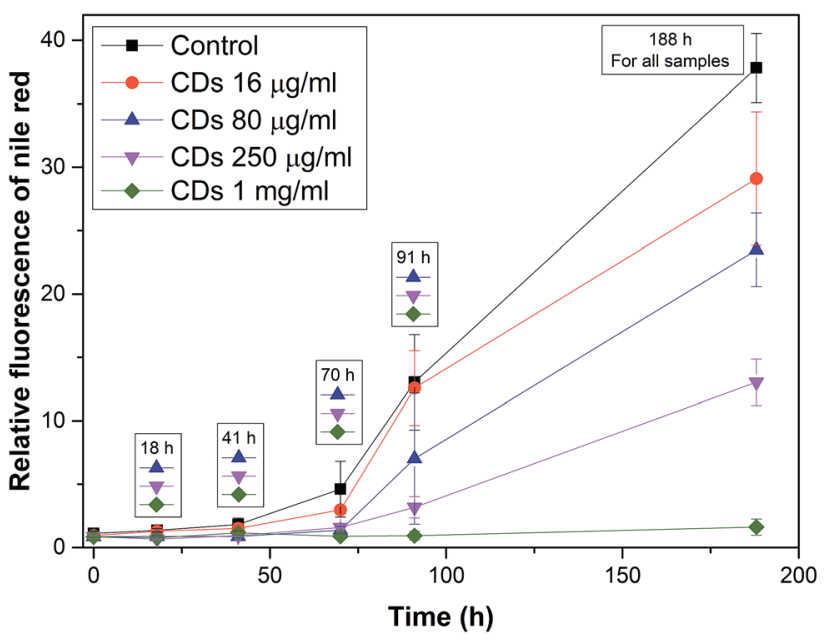

Fig. 13 A graph of the relative fluorescence of NR in experiments with CDs, where the legend above the results from the same time represents a statistically significant difference $(\alpha<0.05)$ when compared to a control at this certain time.

different morphology than of the control. These differences in morphology between the samples containing CDs and the control sample led to a difference in the NR fluorescence. The most plausible mechanism here is that CDs only minimally affect the lag phase, but they efficiently terminate growing fibrils causing their slower growth and shorter lengths (probably similar to the effects of low-molecular-weight aromatic molecules). Interestingly, we found that burnt surfaces are not amyloidogenic, and that the bacterial biofilm created is made of so-called functional amyloids. Therefore "burnt surface" may be a challenge for future applications.

The effect of different concentration of CNPs on the fibril formation is shown in Table 2. It is difficult to compare the results for all nanospecies because, for SWNTs, $\mathrm{C}_{60}$ and NDs ThT was used as the fluorescence dye, and NR was used for CDs. Based on the TEM micrographs and all results, CDs can be added to the previous relationship, and the order of all the CNPs is as follows: NDs $>$ control $>\mathrm{C}_{60}>$ CDs $>$ SWNTs.

We used a small globular protein (HEWL) for our experiments. In a control sample under the selected conditions ( $\mathrm{pH} 2$, $57{ }^{\circ} \mathrm{C}$ ) occurred unfolding protein, subsequent amyloid fibrils formation. The proposed pathway of the amyloid fibril formation of HEWL according to literature ${ }^{59}$ consists of three stages: (1) the formation of dimmers, (2) the formation of protofilaments, and (3) the formation of amyloid fibrils. ${ }^{59}$ In order to generate dimmers, there must be large conformational changes in the secondary structure, the increase in the $\beta$-sheet structure. These changes were achieved by low $\mathrm{pH}$ and high temperature. The structural conversion of the proteins is a key event in the formation of the amyloid fibrils. The created dimmers are the nuclei for the formation of the protofilaments.

What happened when we added CNPs to HEWL. The SWNTs have hydrophobic surface and one side of $\beta$-sheet is also hydrophobic, so the hydrophobic interactions between SWNT and $\beta$-sheet can create a SWNT-HEWL complex. These interactions can lead to blocking of protein chain for further binding with monomer (in our case HEWL with $\beta$-sheet structures) and also it can lead to reduction of population of monomers. Because SWNTs contain $\mathrm{sp}^{2}$-hybridized carbon atoms, not only hydrophobic interactions but also $\pi-\pi$ interactions play a key role in process of inhibition. These interactions can have strong effect on the creation of SWNT-HEWL complex. Their effect can also be in destabilization of $\beta$-sheet structures and prolongation the lag phase. Both theories would sit on our obtained results for SWNTs that SWNTs prolonged the lag phase and are able to inhibit the process of fibrillation. In the literature there are described two contrast effects of carbon nanotubes: (1) MWNTs promote amyloid fibril formation from $\beta_{2}$-microglobulin and (2) SWNTs inhibit amyloid fibril formation from A $\beta$. In contrast to the $\beta_{2}$-microglobulin protein, $A \beta$ peptides had high affinity to carbon nanotubes surface. ${ }^{60}$ From the obtained results with SWNTs, we can also say that HEWL has a high affinity for SWNT. In the case of $\mathrm{C}_{60}$ the key interactions with HEWL are the same ( $\pi-\pi$ and hydrophobic interactions) as for SWNTs, but these nanospecies have a different shape and a surface curvature, which may be the main reason for different influence on the process of fibrillation. Based on the results with SWNTs and $\mathrm{C}_{60}$, we can confirm that $\pi-\pi$ and hydrophobic interactions play a key role in amyloid formation inhibition, but also a shape of nanospecies and a surface curvature can be important for this inhibition. Only a few studies deal with the influence of NDs on the process of fibrillation while they are a promising material for diagnostics. NDs have also hydrophobic $\mathrm{sp}^{3}$-hybridized carbon surface and surface groups, which have a positive charge in our case. This means that adsorption of HEWL on a ND surface proceeded via electrostatic (isoelectric point of HEWL is 11.3 meaning that this protein is anionic under $\mathrm{pH}$ considered in the manuscript) and probably also hydrophobic interactions. The most plausible explanation of influence of NDs on amyloid formation is that NDs have become nuclei for the beginning of 

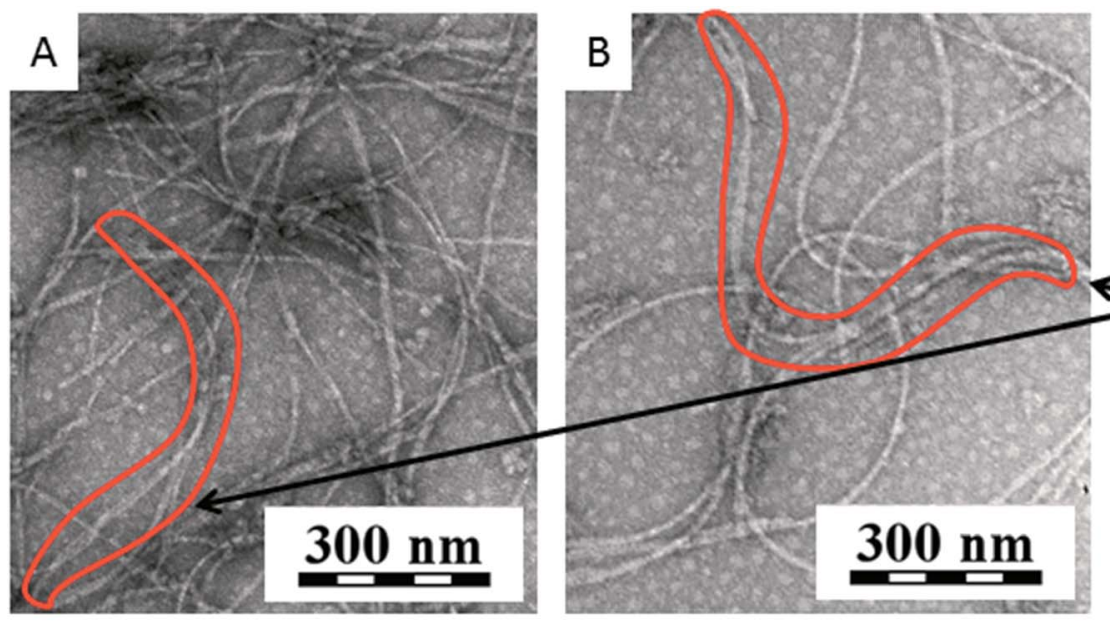
Red highlighted examples of typical amyloid fibrils
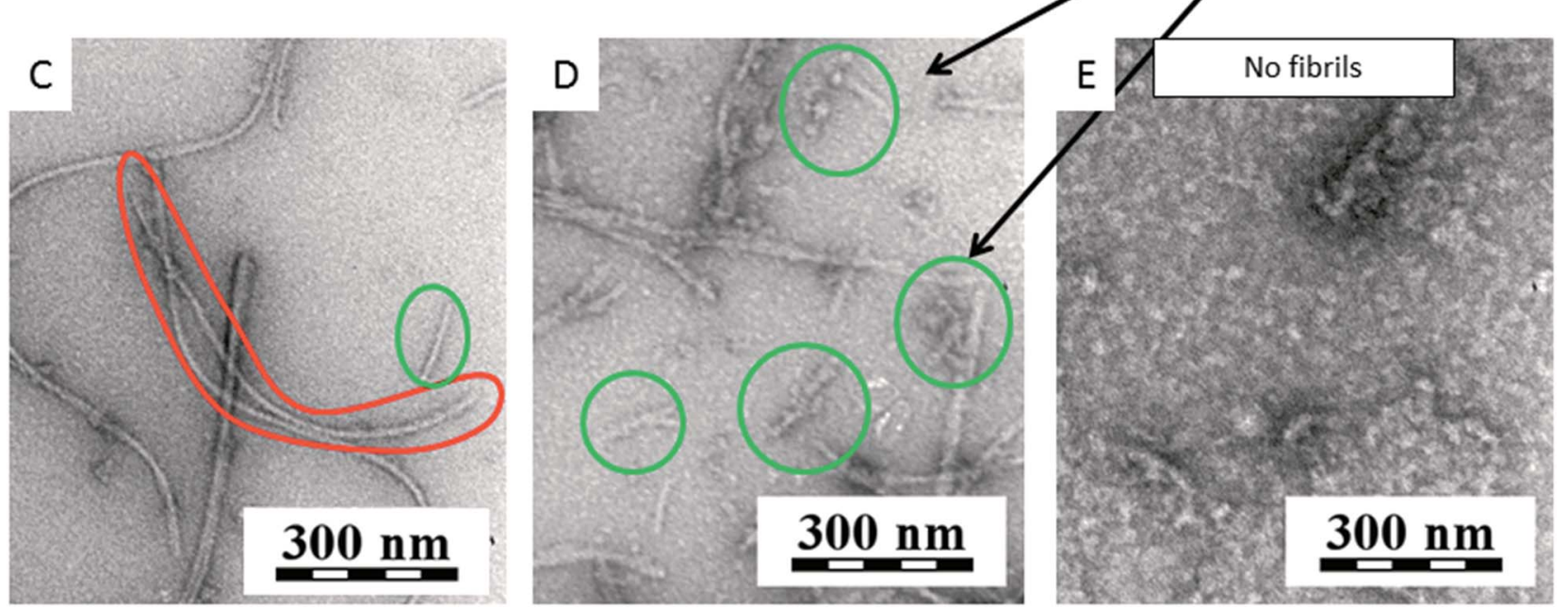

Fig. 14 TEM micrographs of experiments with CDs: (A) fibrils of HEWL (control) after $25 \mathrm{~h}$ of incubation without any nanospecies; (B) fibrils of HEWL after $25 \mathrm{~h}$ of incubation with $16 \mu \mathrm{g} \mathrm{ml}^{-1} \mathrm{CDs}$; (C) fibrils and shorter fibrils of HEWL after $25 \mathrm{~h}$ of incubation with $80 \mu \mathrm{g} \mathrm{ml}^{-1} \mathrm{CDs}$; (D) shorter fibrils of HEWL after $25 \mathrm{~h}$ of incubation with $250 \mu \mathrm{g} \mathrm{ml} \mathrm{m}^{-1} \mathrm{CDs}$. (E) No fibrils of HEWL after $25 \mathrm{~h}$ of incubation with $1 \mathrm{mg} \mathrm{ml}^{-1} \mathrm{CDs}$.

Table 2 The effect of different concentration of CNPs on the fibril formation. The star (*) represents a statistically significant difference compared to a zero concentration of CNPs (control). Bold data represent statistically significant decreases in the fibrillation process compared to the control

\section{$\%$ fibril formation}

\begin{tabular}{|c|c|c|c|c|c|}
\hline $\begin{array}{l}\text { Concentration } \\
\text { of CNPs }\left(\mu \mathrm{g} \mathrm{ml}{ }^{-1}\right)\end{array}$ & 0 & 16 & 80 & 250 & 1000 \\
\hline $\mathrm{SWNT}^{a}$ & $100 \pm 20$ & $22 \pm 6(*)$ & $13 \pm 2(*)$ & $\mathbf{1 1} \pm \mathbf{1}(*)$ & - \\
\hline $\mathrm{NDs}^{a}$ & $100 \pm 20$ & $75 \pm 31$ & $154 \pm 56(*)$ & $344 \pm 110\left(^{*}\right)$ & $646 \pm 276(*)$ \\
\hline $\mathrm{CDs}^{b}$ & $100 \pm 7$ & $77 \pm 14(*)$ & $62 \pm 8(*)$ & $34 \pm 5\left(^{*}\right)$ & $4 \pm 2(*)$ \\
\hline
\end{tabular}

${ }^{a}$ The percent fibril formation was determined from the ThT fluorescence value for $47 \mathrm{~h}$ of incubation in Fig. 8 and $10 .{ }^{b}$ The percent fibril formation was determined from the NR fluorescence values for $188 \mathrm{~h}$ of incubation in Fig. 13.

the fibrillation process significantly shortening the lag phase and an inducing rapid creation of fibrils. CDs significantly decelerated the process of fibrillation. The key interactions between CDs and HEWL are $\pi-\pi$, hydrophobic and probably also electrostatic (however, CDs have negative charged surface groups rather repelling prevailingly negative HEWL molecules).
Based on the results of the influence of four different type of CNPs (NDs, $\mathrm{C}_{60}$, SWNTs, CDs) on formation amyloid fibrils from HEWL, the CNPs can be ranked from the most amyloidogenic to least in the following order NDs $>$ control $>\mathrm{C}_{60}>\mathrm{CDs}$ $>$ SWNTs. 


\section{Experimental}

All materials and methods, such as the preparation of CDs and their characterization or the preparation and characterization of the amyloid fibrils from HEWL, are given in the ESI (holubova_ESI.docx $\dagger$ ).

\section{Conclusions}

From the experiments, we found that NDs promoted amyloid fibril formation. Because the NDs are less toxic than other CNPs $\left(\mathrm{C}_{60}\right.$ or SWNT $),{ }^{19}$ this finding may be interesting information for their production by detonation, in which large quantities of NDs may be released, leading to the formation of amyloid fibrils and subsequent disease in humans. Fibril formation in vivo and the development of the disease is likely to occur over a longer period of time than for in vitro testing. Therefore, it is necessary to take precautions, because the consequences can occur after many years. These experiments showed that the highest concentration of $\mathrm{C}_{60}$ accelerated the process of fibrillation, but smaller concentrations prolonged the lag phase. The risks associated with $\mathrm{C}_{60}$ cannot be excluded; however under good occupational hygiene conditions, the risk is low. ${ }^{61}$ On the basis of the performed experiments, it is important to be take care, especially in applications in medicine, as $\mathrm{C}_{60}$ may cause a negative reaction with proteins, which may lead to the formation of amyloid fibrils. A different situation occurred for SWNTs. These nanospecies significantly prolonged the lag phase of amyloid formation. Although a higher toxicity is known for SWNTs than for $\mathrm{C}_{60},{ }^{62}$ but these results are of interest for drug development. Interestingly, CDs significantly affected the process of fibrillation; as the process was decelerated for almost all concentrations. It seems that CDs efficiently terminate fibril growth. The big advantages of CDs are their excellent biological properties such as low toxicity and good biocompatibility, making their applications in medicine as a drug delivery system possible. The studied CNPs (NDs, $\mathrm{C}_{60}$, SWNTs and CDs) exhibited different behaviors in the presence of HEWL. The amyloidogenicity of studied nanomaterials was not observed in physiological conditions but was in the most suitable condition in which HEWL easily forms fibrils. It should be emphasized that HEWL is only a model system that is very suitable for testing, but the results obtained may not be consistent with proteins and peptides that are the cause of the amyloidosis in humans. Furthermore, in vitro testing was studied which may or may not reflect the real effects in vivo. Nevertheless, the results show an interesting comparison of four different types of CNPs based on various applications.

\section{Conflicts of interest}

There are no conflicts to declare.

\section{Acknowledgements}

The authors thank Mariia Rabyk, MSc. for preparation of the graphical abstract and Fig. 1. The authors acknowledge financial support from the Ministry of Education, Youth and Sports of the Czech Republic (grant \# LM2015064 ERIC), from the Ministry of Health of the Czech Republic (grant \# 16-30544A) and from the Czech Grant Foundation (grant \# 16-03156S). OPG and J. S. acknowledge the support from the European Regional Development Fund OPPK (CZ.2.16/3.1.00/21545). J. H. thanks projects TE01020118 (Technology Agency of the CR) and POLYMAT LO1507 (Ministry of Education, Youth and Sports of the CR, program NPU I).

\section{References}

1 S. E. Radford and J. S. Weissman, J. Mol. Biol., 2012, 421, 139-141.

2 K. Sideras and M. A. Gertz, Adv. Clin. Chem., 2009, 47, 1-44. 3 D. M. Fowler, A. V. Koulov, C. Alory-Jost, M. S. Marks, W. E. Balch and J. W. Kelly, PLoS Biol., 2006, 4, 0100-0107.

4 B. P. C. Hazenberg, Rheum. Dis. Clin. North Am., 2013, 39, 323-345.

5 I. Cherny and E. Gazit, Angew. Chem., Int. Ed., 2008, 47, 40624069.

6 C. Iannuzzi, R. Maritato, G. Irace and I. Sirangelo, Int. J. Mol. Sci., 2013, 14, 14287-14300.

7 J.-C. Rochet and P. T. Lansbury, Curr. Opin. Struct. Biol., 2000, 10, 60-68.

8 E. Gazit, FEBS J., 2005, 272, 5971-5978.

9 K. E. Marshall, K. L. Morris, D. Charlton, N. O'Reilly, L. Lewis, H. Walden and L. C. Serpell, Biochemistry, 2011, 50, 2061-2071.

10 F. Chiti and C. M. Dobson, Annu. Rev. Biochem., 2006, 75, 333-366.

11 E. Y. Chi, S. Krishnan, T. W. Randolph and J. F. Carpenter, Pharm. Res., 2003, 20, 1325-1336.

12 L. E. Murr and K. F. Soto, Mater. Charact., 2005, 55, 50-65.

13 G. D. Nielsen, M. Roursgaard, K. A. Jensen, S. S. Poulsen and S. T. Larsen, Basic Clin. Pharmacol. Toxicol., 2008, 103, 197208.

14 K. Aschberger, H. J. Johnston, V. Stone, R. J. Aitken, S. M. Hankin, S. A. K. Peters, C. L. Tran and F. M. Christensen, Crit. Rev. Toxicol., 2010, 40, 759-790.

15 S. Banerjee, T. Hemraj-Benny and S. S. Wong, Adv. Mater., 2005, 17, 17-29.

16 A. Krueger, J. Mater. Chem., 2008, 18, 1485.

17 V. N. Mochalin, O. Shenderova, D. Ho and Y. Gogotsi, Nat. Nanotechnol., 2012, 7, 11-23.

18 A. Krueger, Adv. Mater., 2008, 20, 2445-2449.

19 V. N. Mochalin, O. Shenderova, D. Ho and Y. Gogotsi, Nat. Nanotechnol., 2012, 7, 11-23.

20 A. Krueger, J. Mater. Chem., 2008, 18, 1485.

21 Y. Wang and A. Hu, J. Mater. Chem. C, 2014, 2, 6921.

22 P. G. Luo, S. Sahu, S.-T. Yang, S. K. Sonkar, J. Wang, H. Wang, G. E. LeCroy, L. Cao and Y.-P. Sun, J. Mater. Chem. B, 2013, 1, 2116-2127.

23 R. Jelinek, in Carbon Quantum Dots: Synthesis, Properties and Applications, Springer International Publishing, 2017, pp. 527. 
24 D. Qu, M. Zheng, L. Zhang, H. Zhao, Z. Xie, X. Jing, R. E. Haddad, H. Fan and Z. Sun, Sci. Rep., 2014, 4, 5294.

25 X. Zhai, P. Zhang, C. Liu, T. Bai, W. Li, L. Dai and W. Liu, Chem. Commun., 2012, 48, 7955.

26 X. Guo, C.-F. Wang, Z.-Y. Yu, L. Chen and S. Chen, Chem. Commun., 2012, 48, 2692-2694.

27 J. Shen, Y. Zhu, X. Yang and C. Li, Chem. Commun., 2012, 48, 3686.

28 W. Liu, C. Li, Y. Ren, X. Sun, W. Pan, Y. Li, J. Wang and W. Wang, J. Mater. Chem. B, 2016, 4, 5772-5788.

29 Y. Wang and A. Hu, J. Mater. Chem. C, 2014, 2, 6921.

30 X. Cao, J. Ma, Y. Lin, B. Yao, F. Li, W. Weng and X. Lin, Spectrochim. Acta, Part A, 2015, 151, 875-880.

31 X. Zhai, P. Zhang, C. Liu, T. Bai, W. Li, L. Dai and W. Liu, Chem. Commun., 2012, 48, 7955.

32 H. Zhu, X. Wang, Y. Li, Z. Wang, F. Yang and X. Yang, Chem. Commun., 2009, 5118.

33 S. Dey, P. Chithaiah, S. Belawadi, K. Biswas and C. N. R. Rao, J. Mater. Res., 2014, 29, 383-391.

34 V. Milosavljevic, A. Moulick, P. Kopel, V. Adam and R. Kizek, J. Metallomics Nanotechnol., 2014, 3, 16-22.

35 M. L. Bhaisare, A. Talib, M. S. Khan, S. Pandey and H. F. Wu, Microchim. Acta, 2015, 182, 2173-2181.

36 S. Dey, P. Chithaiah, S. Belawadi, K. Biswas and C. N. R. Rao, J. Mater. Res., 2014, 29, 383-391.

37 W. Wei, C. Xu, L. Wu, J. Wang, J. Ren and X. Qu, Sci. Rep., 2014, 4, 1-7.

38 J. Jiang, Y. He, S. Li and H. Cui, Chem. Commun., 2012, 48, 9634.

39 A. Cao, D. Hu and L. Lai, Protein Sci., 2004, 13, 319-324.

40 Y. Tokunaga, M. Matsumoto and Y. Sugimoto, Int. J. Biol. Macromol., 2015, 80, 208-216.

41 R. Swaminathan, V. K. Ravi, S. Kumar, M. V. S. Kumar and N. Chandra, Adv. Protein Chem. Struct. Biol.Adv. Protein Chem. Struct. Biol., 2011, 84, 63-111.

42 F. Gottschalk, T. Sonderer, R. W. Scholz and B. Nowack, Environ. Toxicol. Chem., 2010, 29, 1036-1048.

43 C. Li and R. Mezzenga, Nanoscale, 2013, 5, 6207-6218.

44 G. Socrates, Infrared and Raman characteristic group frequencies: tables and charts, John Wiley, New York, 2001.
45 O. Pop-Georgievski, N. Neykova, V. Proks, J. Houdkova, E. Ukraintsev, J. Zemek, A. Kromka and F. Rypaček, Thin Solid Films, 2013, 543, 180-186.

46 J. Pleštil, Makromol. Chem., Macromol. Symp., 1988, 15, 185190.

47 J. Lindon, NMR Biomed., 1999, 12, 168.

48 G. Rambabu and S. D. Bhat, Electrochim. Acta, 2015, 176, 657-669.

49 V. S. Nair, R. D. Mukhopadhyay, A. Saeki, S. Seki and A. Ajayaghosh, Sci. Adv., 2016, 2, e1600142.

50 J. Robertson, Adv. Phys., 1986, 35, 317-374.

51 P. C. Ke, M.-A. Sani, F. Ding, A. Kakinen, I. Javed, F. Separovic, T. P. Davis and R. Mezzenga, Chem. Soc. Rev., 2017, 110, 1221-1232.

52 S. Freire, M. H. De Araujo, W. Al-Soufi and M. Novo, Dyes Pigm., 2014, 110, 97-105.

53 R. Mishra, D. Sjölander and P. Hammarström, Mol. BioSyst., 2011, 7, 1232.

54 M. Biancalana and S. Koide, Biochim. Biophys. Acta, Proteins Proteomics, 2010, 1804, 1405-1412.

55 R. Mishra, D. Sjölander and P. Hammarström, Mol. BioSyst., 2011, 7, 1232.

56 M. M. Picken and G. A. Herrera, Amyloid and Related Disorders, Humana Press, Totowa, NJ, 2012.

57 V. N. Uversky and Y. Lyubchenko, Bio-Nanoimaging: Protein Misfolding \& Aggregation, Elsevier Inc., 2013.

58 A. Fibrils, L. J. Waddington, S. L. Gras, L. J. Waddington and K. N. Goldie, Protein Folding, Misfolding, and Disease, Humana Press, Totowa, NJ, 2011, vol. 752.

59 Y. Yonezawa, S. Tanaka, T. Kubota, K. Wakabayashi, K. Yutani and S. Fujiwara, J. Mol. Biol., 2002, 323, 237-251.

60 C. Li and R. Mezzenga, Nanoscale, 2013, 5, 6207-6218.

61 K. Aschberger, H. J. Johnston, V. Stone, R. J. Aitken, C. L. Tran, S. M. Hankin, S. A. K. Peters and F. M. Christensen, Regul. Toxicol. Pharmacol., 2010, 58, 455-473.

62 G. Jia, H. Wang, L. Yan, X. Wang, R. Pei, T. Yan, Y. Zhao and X. Guo, Environ. Sci. Technol., 2005, 39, 1378-1383. 